\title{
Saywaña, amojonamientos y deslindes en Villablanca y Chulluncane: geografía de un conflicto de tierras aimara ${ }^{1}$
}

\author{
Raúl Molina Otárola²
}

\begin{abstract}
RESUMEN
Los conflictos de tierras en comunidades aimara, a pesar de ser numerosos, han sido poco estudiados. Este artículo se adentra en el examen de las contradicciones por dominios de tierras entre las comunidades de Chulluncane y Villablanca del altiplano de Tarapacá. Analiza la dimensión simbólica y material de las disputas territoriales, el carácter histórico de las desavenencias y los aportes de geógrafos y otros cientistas para comprenderlos. Se adentra en la geografía de las demarcaciones, explicando los conceptos de saywaña, amojonamiento y deslindes, ocupados para entender las contiendas de tierras en la zona andina. Plantea que bajo el periodo colonial y la República del Perú, no se produjeron conflictos abiertos de tierras entre estas comunidades. Las contradicciones y disputas se desataron con la aplicación de la política de tierras impuesta por Chile, que favoreció la constitución sucesiva y sobrepuesta de títulos de dominio que dieron origen a conflictos de tierras aimara.
\end{abstract}

Palabras clave: Chile, Aimara, Propiedad, Conciliación y Conflicto de Tierras.

\begin{abstract}
Land conflicts in Aymara communities, despite being numerous, have been rarely studied. This article explores the contradictions in land ownership between the communities of Villablanca and Chulluncane, in the altiplano region of Tarapacá, Northern Chile. It also analyzes the symbolic and material dimensions of these territorial disputes, the historic nature of the disagreements and the contributions of geographers and other scientists in understanding them. We focus on issues of geographic demarcations, explaining the concepts of saywaña, demarcation and boundaries used to understand land disputes in the Andes. This concept states that for two hundred years, between the 18th and 19th centuries, during colonial times in the Republic of Peru, no open land disputes occurred between these communities. The territorial disputes broke out with the application of land policy imposed by the Chilean State, which favored the establishment of successive and superimposed titles or deeds, which gave rise to conflicts on Aymara lands.
\end{abstract}

Key word: Chile, Aymara, Property, Conciliation and Lands Conflict.

\footnotetext{
1 Este artículo forma parte del proyecto FONDECYT $N^{\circ} 1150876$. Artículo recibido el 11 de mayo de 2015, aceptado el 19 de agosto de 2015 y corregido el 16 de septiembre de 2015 .
}

\footnotetext{
2 Geógrafo y Doctor en Antropología (Chile). E-mail: raul17molina@gmail.com
} 
"Norte de Chile. Altiplano de la Región de Tarapacá. La comuna de Colchane está formada por varios poblados andinos y estancias de comunidades aimara, constituidas por familias emparentadas y unidas a un territorio. Uno de estos poblados es Cariquima, arribamos al pueblo con una antigua iglesia, probablemente del siglo XVIII. Avanzamos hacia el sur, por el costado oriente del cerro Huanapa y muy cerca de la frontera con Bolivia, ingresamos a las tierras de la comunidad de Villablanca. En el pueblo no hay gente, la sede comunitaria está cerrada. Seguimos camino al sur, hacia Templanza, un lugar al lado del río que posee un extenso bofedal donde pastan alpacas y algunas llamas. Antes de llegar, sobre la cima de un pequeño cerro, observamos a numerosas personas vestidas con ponchos y sombreros, y mujeres con polleras, todos sentados alrededor de una mesa vestida con un 'aguayo'. Abajo, en las faldas del morro, varios vehículos están estacionados. Nos acercamos y subimos hasta el grupo de personas. Saludamos y preguntamos si este es el lugar de la reunión citada. Contestan que sí. Pensábamos que sería en una sede comunitaria, pero es al aire libre. Luego explican que el morro Templanza, la pequeña colina donde nos encontramos, es uno de los puntos donde pasa el deslinde norte de la comunidad y pueblo de Chulluncane. Por eso están allí todos los Challapa, para que las autoridades de gobierno así lo reconozcan. Enseguida comentan que están solo ellos. Alguien pregunta, ¿por qué la gente de Villablanca no asistió a la reunión? Contestan que los Chambe, Mamani y Mollo están en otro cerro. Concurrimos al lugar ubicado a unos 2,5 a 3 kilómetros más al sur, y volvemos a ver a lo lejos, gente parada y sentada en torno a una mesa, en son de espera. Están en la cima de otro pequeño cerro Ilamado Chotocollo, son los comuneros de Villablanca. Detrás asoman las primeras casas del poblado de Chulluncane. Preguntamos ipor qué no están juntos a los de Chulluncane para realizar la reunión?, contestan que ellos están en los deslindes ancestrales de las tierras de Villablanca, y no se moverán del lugar. Volvemos a preguntar; ipor qué no se juntan para discutir y llegar a un acuerdo? responden, que los de ChuIluncane vengan a nuestro cerro, pues el morro Templanza donde se encuentran, son tierras de Villablanca. En seguida nos pasan un legajo de copias de documentos que parecen ser títulos de tierras y de propiedad, algunos muy antiguos y otros con timbres de notarios y conservadores, reconocibles del siglo XX. Volvemos al morro Templanza donde están los ChaIlapa de Chunlluncane para preguntarles si pueden desplazarse hacia el cerro Chotocollo donde se encuentra reunida la gente de Villablanca. La respuesta es negativa, "nosotros estamos en la línea que nos pertenece por el título de propiedad de 1912". Nos transfieren otro dossier de documentos. Comprendemos que no es posible reunir a Chulluncane con Villablanca, a los Challapa con los Chambe, Mamani y Mollo, y viceversa. De por medio hay tierras en conflicto, marcadas por dos promontorios que hacen de límites y fronteras inamovibles, el morro Templanza y el cerro Chotocollo. Estos promontorios expresan simbólica y materialmente un conflicto etnoespacial, cuya profundidad en el tiempo desconocemos, así como su magnitud territorial. Atisbamos que hay una ancha franja de tierra en juego, que incluye un extenso y codiciado pastizal y bofedal Ilamado Templanza y Atipa, y sectores denominados Chuallani y Llachupaica, tierras que forman parte de un largo y al parecer irreparable conflicto territorial intraétnico ${ }^{3 \prime}$.

En este artículo interesa desentrañar el origen del conflicto territorial entre las comunidades aimara de Chulluncane y Villablanca y responder: ¿Cuáles son los componentes geográficos culturales de un conflicto de tierras aymara? ¿Cómo se origina esta contradicción

\footnotetext{
3 El planteamiento del problema de este artículo, es un relato etnográfico del autor referido a lo ocurrido en mayo de 1996, durante el primer encuentro con las comunidades aimara de Villablanca y Chulluncane, con motivo de iniciarse un estudio históricoterritorial conducente a un proceso de conciliación, en virtud del artículo 39 letra d, del Título III, Párrafo $2^{\circ}$, del artículo 55 y 56 de la Ley Indígena 19.253 de 1993. Este estudio fue encargado al autor y a Martín Correa, por la Subdirección Norte de la Corporación Nacional de Desarrollo Indígena.
} 
de demandas territoriales? ¿Cuál es el factor detonante del conflicto territorial intraétnico?

El relato etnográfico inicial plantea un conflicto de tierras. La ubicación de los miembros de las comunidades de Chulluncane y Villablanca en los cerros morro Templanza y Chotocollo, es una expresión simbólica y material de este, como señala Godelier (1984: 187), pues la parte conceptual de lo real es tan concreta como su parte material. Las reuniones en cada cerro simbolizan el problema, cada cual demandando un deslinde, y es material pues se trata de un pedazo de terreno que escurre entre los dos cerros. Este conflicto contemporáneo, plantea antiguas cuestiones del Mundo Andino, referidas a la constitución de los límites y/o fronteras de tierras, de ayllus y de territorios étnicos, cuestión que se expresa a los menos desde la época incaica, cuando el Tawantinsuyu iniciara amojonamientos, demarcaciones y deslindes en las tierras de su vasto territorio imperial (Harris, 1997).

Los cerros Templanza y Chotocollo son símbolos del paisaje, hitos geográficos socialmente demarcados y connotados culturalmente por cada comunidad. Los miembros de ellas, al situarse en sus cimas, hacen una demostración simbólica del problema y señalan sus pretensiones de dominio. La distancia entre cerros es proporcional a la falta de acuerdo. Las voluntades colectivas, tal como los cerros, aparecen como posiciones inamovibles. Por ello, la presencia de los comuneros de Chulluncane y Villablanca en cerros distintos, constituye un simbolismo geográfico cultural, que nos habla de una toma de posesión, de un acto de infantería, y de pretensiones de dominios traslapados, que dan origen a la disputa territorial de una franja aproximada de 2,5 a 3 kilómetros que corre en dirección este y oeste, entre los dos cerros (Figura $N^{0} 1$ ).

Los documentos adjuntados por las COmunidades de Chulluncane y Villablanca corresponden a inscripciones notariales, actas de acuerdos conciliatorios y títulos de dominios, entregados por instituciones coloniales y republicanas, tanto en tiempos de la administración del Perú (1821-1879), como bajo la chilena. De las instituciones republicanas, destacan los documentos otorgados por los Juzgados de Paz de la República del Perú, entre las décadas de 1850 y 1870, y las inscripciones de dominio y actas de conciliación territorial realizadas en el siglo XX, bajo la jurisdicción de Chile. Estos documentos aportan información territorial de Chulluncane y Villablanca de tres siglos. En ellos, aparecen los mismos territorios en conflictos y se repiten los linajes actuales: Challapa, Chambe, Mollo y Mamani. Se hace presente, que el conflicto de tierras se sustenta solo en títulos de propiedad constituidos a principios del siglo XX, bajo el imperio de la legislación chilena. En este periodo, las instituciones que resguardan el dominio de tierras, los Conservadores de Bienes Raíces, se localizan lejos de la zona andina de Tarapacá, y actúan aplicando el Código Civil, de evidente influencia francesa, que entró en vigor en Chile en 1857, cuya lógica liberal se comenzó a aplicar en Arica y Tarapacá a partir de 1887 (Ruz, 2014). Este Código estableció que la única propiedad que existe es la inscrita (Martinic y Tapia, 2005). Ahora bien, la distancia geográfica entre la ciudad y las tierras interiores, favorece la formación de nuevas propiedades con deslindes redactados a discreción de los solicitantes aimara que concurren a inscribirlas desde aislados lugares altiplánicos o de los valles interiores. En algunos casos, los deslindes redactados en los títulos de dominio, serán expresión de antiguas pretensiones territoriales contenidas desde el periodo colonial y republicano del Perú. Incluso, los conflictos de tierras andinos pueden reconocerse en épocas prehispánicas, cuando ya existía en lengua aimara, la palabra Checa cuscachiri, "justo juez", el que sabe igualar de forma derecha y verdadera (Bertonio, 1984 [1612] I: 276 y II: 60,78; Harris, 1997: 370).

El conflicto de tierras simbolizado en el cerro Templanza y Chotocollo, está retratado en escrituras de dominio constituidas a principios del siglo XX. La comunidad de Chulluncane señala que sus deslindes en terreno, de acuerdo al título de propiedad de 1912 son: "Al Norte, Ojo de agua de La Calacane y un morro en ciénega de Templanza; al Sur, punta del Cerro Sillaguaya; al Este, punta del Cerro Blanco y Cerro Charcollo; y al Oeste, Apacheta de Chijulla y ojo de agua de Panalla" ${ }^{4}$. Por su parte,

\footnotetext{
4 Compraventa Mariano Cruz Challapa a Esteban Challapa, inscrita a Fojas 457 NN$^{\circ} 545$ del Registro de Propiedades del Conservador de Bienes Raíces de Iquique, del año 1912.
} 
la comunidad de Villablanca en virtud de varios títulos de 1915 a 1917, reivindica las tierras comprendidas en los siguientes deslindes de su parte sur: "Cerro Ancocollo a los cerros Chapasane, Belacollo, Viscachirí, Chotocollo, Alto Tacore hasta el lugar Guaivarane y Cerro Tres Llaretas" (Molina et al., 1997).

Estos deslindes incluyen los dos cerros simbólicos del relato etnográfico y agregan nuevos hitos visibles de la geografía comunal, que dibujan una larga faja de tierras en conflicto. Los deslindes van uniendo cerros, apachetas y ojos de aguas, que los españoles Ilamaron "mojones" (Harris, 1997). Estos deslindes al estar traslapados, generan una superposición de títulos de dominio “...en una franja promedio de aproximadamente 3 kilómetros de ancho por 10 kilómetros de largo, lo que implica una superficie en conflicto de alrededor de 3.000 hectáreas" (Molina et al., 1997: 8). Dentro de esta franja de tierra se localizan importantes recursos para la ganadería, la agricultura y el poblamiento. La tierra en litigio contiene un extenso bofedal, varias chacras, infraestructura agrícola, casas, vertientes y campos de pastoreo.

El problema de la superposición de los títulos de propiedad entre las comunidades aimara de Villablanca y Chulluncane, plantea un tipo de conflicto andino que ha sido poco

Figura $\mathrm{N}^{\circ} 1$

Zona de conflicto de tierras comunidades aimara Villablanca y Chulluncane

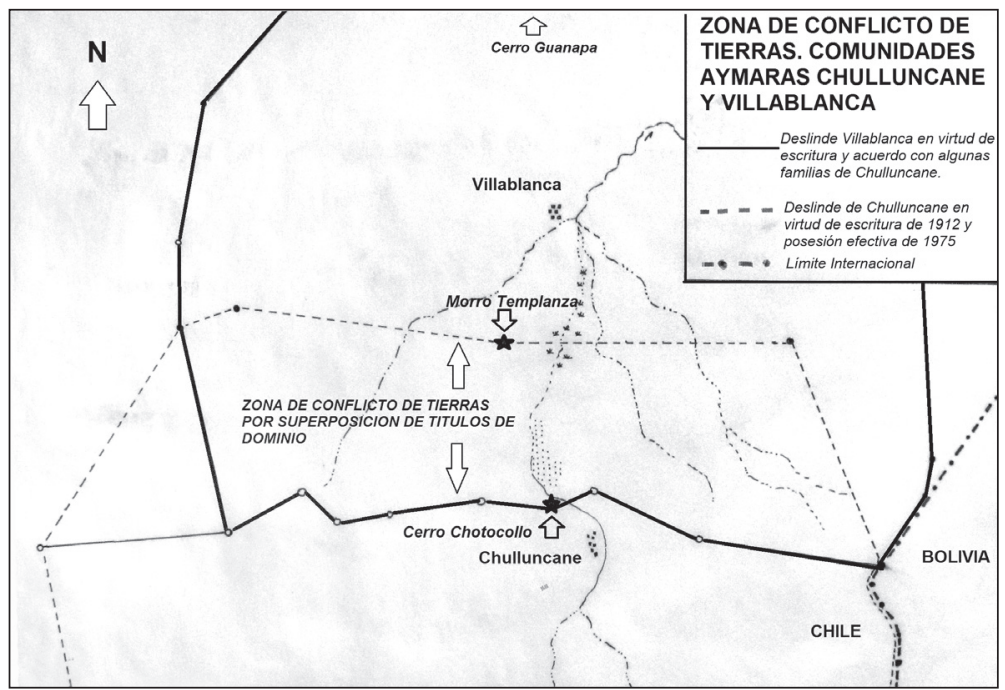

Fuente: Elaboración propia.

tratado por las ciencias sociales, y bosqueja interrogantes y desafíos geográficos para comprender los paisajes, los lugares, los territorios y los espacios andinos en disputa intraétnica. Abordar estos problemas geográficos, requiere de una perspectiva diacrónica que dé cuenta de sus dinámicas, cambios y permanencias del conflicto territorial. Esta aproximación convoca como pasadizo teórico analítico a la geografía histórica, como lectura especializada de los hechos, la cultura y el paisaje (Sauer, 1940; Samarkin, 1981), a una geografía de época, que pone acento en el significado y significante de los conceptos geográficos utilizados en diversos contextos históricos y culturales (Molina, 2010) y echa mano a métodos de análisis contemporáneos como la geografía cultural, relacionados con los territorios y el paisaje que son construcciones espaciales modeladas social y culturalmente (Claval, 1999), donde se mantiene conectado e interdependiente al espacio natural con el espacio social (Fernández, 2006). Estas aproximaciones teóricas geográficas favorecen el entendimiento de una parte, la jurídico-territorial, de la compleja 
formación del espacio andino, y permite analizar el conflicto de tierras intraétnico como reivindicaciones discursivas de cada comunidad aimara, donde el poder, el espacio y las representaciones simbólicas y materiales se hacen presentes en la contradicción territorial (Gregory, 1996).

\section{Geografía y estudios territoriales andinos}

La problemática de los deslindes de tierras y de las superposiciones de títulos de dominio, en las comunidades aimara de Villablanca y Chulluncane, impone desafíos geográficos-metodológicos para desentrañar la estrecha relación entre comunidad, cultura y paisaje, que están presentes en esta contradicción territorial intraétnica. Es preciso adoptar una mirada espacial del conflicto y aproximarse de este modo al estudio de los documentos que contienen en su redacción, como reflejo del espacio geográfico, los topónimos e hitos del paisaje que están escritos en las minutas de deslindes. Estos deslindes nombran los accidentes geográficos que cercan simbólica y materialmente los dominios territoriales de cada comunidad. La información geográfica contenida en el documento debe ser localizada en terreno y verificada su correspondencia. Para ello, se acude al conocimiento geográfico propio y a la memoria histórica y colectiva de los habitantes de cada comunidad aimara, a fin de identificar los topónimos y los accidentes geográficos descritos. En algunas ocasiones, la memoria de los aimara más longevos opera como desciframiento de una "arqueo-toponimia", es decir, localiza en el espacio geográfico viejos nombres en desuso, que constituyen marcas claves para representar cartográficamente la transformación de los deslindes que aparecen en los documentos coloniales y republicanos. Los trazados de deslindes al ser reconstruidos en el tiempo, permiten comprender la génesis y el desarrollo del conflicto territorial. Las escrituras, a su vez, permiten comprender el componente social del conflicto, es decir, la relación entre parentesco, tierras y comunidad que se expresa en la contradicción territorial entre comunidades aimara.

La geografía y los geógrafos han realizado algunos aportes al estudio de este tipo de problemáticas andinas, siendo más numerosas las contribuciones realizadas desde la antropología y la etnohistoria. En los Andes del Perú, el geógrafo francés Olivier Dollfus (1991) desarrolló un programa de investigación acerca de aspectos ambientales y de la formación del espacio andino en periodos incaicos, coloniales, republicanos y actuales. En Chile, recientemente Cunill (2014) ha propuesto de modo general nuevos estudios y desafíos de la geografía histórica para el área andina. Las problemáticas referidas al mundo aimara han sido investigadas por el geógrafo Freddy Taberna, fusilado en Pisagua en 1973, quien contribuyó con varios trabajos, además de promotor del Primer Congreso del Hombre Andino (Núñez, 2015). En la temática específica de los deslindes, demarcaciones, fronteras y límites territoriales y étnicos, el geógrafo francés Thierry Saignes (1985, 1986, 1990) ha efectuado reconocidos y valiosos aportes, especialmente en el estudio de la administración territorial incaica en Bolivia y de otros grupos étnicos contemporáneos de la región. Él contribuyó con un marco de análisis geográfico para la comprensión del mundo andino, a fin de conocer su ordenamiento espacial, sus conflictos y las formas culturales de construcción del territorio, donde lo cartográfico jugaba un papel esclarecedor de los procesos geográficos-históricos ${ }^{5}$.

Entre los aportes a la comprensión del ordenamiento del espacio andino se encuentra la creación de varios modelos teóricos, siendo el más clásico, el planteado por el antropólogo John Murra (1972, 1973, 1975), referido a la complementariedad productiva de diferentes pisos ecológicos, el que ha sido señero para vislumbrar los procesos de asentamiento y cooperación intersocietal basados en la complementariedad de productos de diversas zonas ecológicas en la gradiente altitudinal, aplicable a tiempos prehispánicos

\footnotetext{
5 "Thierry Saignes era geógrafo de formación, y ha descrito el placer que era el caminar en las montañas y ver un inmenso paisaje delante de sus ojos. De hecho, en sus trabajos de investigación, los mapas jugaban un papel importante... Su estilo intelectual también era cartográfico. Buscaba siempre una visión global y panorámica de la realidad histórica, en que los ejemplos específicos cobraban forma en un marco amplio, tanto geográfico como temporal" (Harris, 1997: 351).
} 
tardíos y coloniales en los Andes. Igualmente, Núñez y Dillehay (1979) desarrollaron el Ilamado modelo de "Movilidad Giratoria", y al mismo tiempo, Browman (1980) concibe el modelo "Modo Altiplano", ambos operando en momentos prehispánicos en el norte de Chile y altiplano boliviano, respectivamente, en el ámbito de la circulación de productos a través de caravanas de llamas y relaciones sociales. En estos últimos modelos, la actividad de caravaneo es fundamental para comprender la interacción social, económica y política entre las tierras altas y las tierras bajas del área Sur Andina (Berenguer, 2004). El modelo de John Murra tiene la particularidad de concebir un ordenamiento geográfico de complementación ecológica de los territorios étnicos prehispánicos, que se diferencia de las concepciones modernas de territorios únicos y exclusivos, en los que se supone correspondencia entre un grupo étnico y un territorio. Murra propone el entendimiento del espacio andino como "... asentamientos discontinuos, espacios compartidos, y rutas que unen 'islas' de cada grupo en una especie de archipiélago" (Harris, 1997: 357). Se trata de comprender la existencia de múltiples asentamientos, ocupados por diversos grupos étnicos, localizados en disímiles pisos ecológicos (Murra,1973,1975). Por su parte, MoliniéFioravanti (1986-1987) trabaja las fronteras de los Andes en tiempos del Inca desde una perspectiva simbólica, poniendo atención en los aspectos sociales y de la naturaleza que generan deslindes y fronteras territoriales, incluyendo lugares rituales que demarcan estos espacios. Olivia Harris (1997) complementa esta visión, al abordar en sus detallados trabajos, el problema de los deslindes o mojones en los espacios étnicos andinos.

Entre los estudios territoriales del periodo colonial en el área andina de Bolivia, destaca el trabajo de Tristan Platt, quien usando mapas se adentra a comprender los conflictos en la comunidad de Chayanta, y estudia las delimitaciones y amojonamientos de tierras entre los Macha (Platt, 1978, 1982). Para los aimara del norte de Chile, sobresalen los trabajos etnohistóricos de Jorge Hidalgo, especialmente los referidos a demarcaciones de cacicazgos y composiciones de tierras indígenas $(\mathrm{Hi}-$ dalgo et al., 1990). Destacable es el trabajo etnográfico de Gabriel Martínez, sobre la constitución del espacio andino en Isluga, a través de los cerros y sitios rituales de los Uywiris (Martínez, 1976). También, el estudio de los antropólogos Gundermann y González (1997) sobre las transformaciones históricas en el espacio andino en virtud de la formación de la propiedad aimara, el que constituye un aporte específico al conocimiento de la formación de la propiedad territorial de la zona de Arica y Tarapacá. Igualmente, la formación de la propiedad andina es estudiada por Ruz (2014) y recientemente algunos autores analizan las contradicciones sociales y políticas internas en comunidades andinas, como Socoroma (Choque, 2015). Específicamente, el conflicto de tierras en comunidades aimara es ensayado por Gundermann (2005), y previamente se desarrolla el estudio de Molina et al. (1997) sobre las contradicciones territoriales de las comunidades que se analizan en este artículo.

Los estudios nombrados, entre otros, permiten adentrarse en la comprensión de las circunstancias históricas en que ocurren los conflictos de tierras en el altiplano y, específicamente, entre las comunidades de Villablanca y Chulluncane. Ellos ayudan a auscultar y comprender los orígenes de una contradicción territorial que se expresa abiertamente en el periodo republicano chileno, cuando se aplicó una política liberal de constitución del dominio de las tierras, basado en el reglamento del Conservador de Bienes Raíces. En sí mismo este procedimiento es un laisse faire, debido a las distancias geográficas y culturales, entre las instituciones del Estado nacional y las comunidades aimara, lo que dio paso a numerosos problemas de tierras contemporáneos en el altiplano de Tarapacá.

\section{Demarcaciones y conflictos de tierras: Saywaña, mojones y deslindes}

Las demarcaciones de territorios étnicos y de tierras de comunidades, se remontan a periodos prehispánicos (Harris, 1997; Saignes, 1990; Molinié-Fioravanti, 1986-1987). Entre los aimara, las marcas de deslindes se conocían con el nombre de saywas (Bertonio 1984). En el periodo colonial, siglos XVI al XVIII, fue el amojonamiento el concepto más ocupado para la demarcación de tierras, y el concepto deslinde, es usado profusamente 
en el siglo XIX, sirviendo para la redacción de títulos de dominio a través de los puntos cardinales -Norte, Sur, Este y Oeste-, que constituyen el cuerpo cierto de las escrituras de propiedad, expedidas por los gobierno de Perú y luego de Chile.

En la demarcación de tierras aimara se han usado distintos conceptos de época que significan lo mismo. Mojón es una "señal", su homólogo en aimara es qillinqa, saywa, chuta, palabras que significan "montón de piedras puesto por mojón". El acto de "lindar, mojonar" se denomina con las palabras saywaña, qillinkaña, qurpachaña (Bertonio, 1984: 276, 447). El amojonamiento considera también a las señas del paisaje. "Los mojones variaban en su forma física: torrecitas de piedra tallada al estilo inka, piedras paradas, montones de piedras o terrones, o hitos del mismo paisaje tales como ríos o cerros" (Harris, 1997: 365). Los cerros y otros accidentes del paisaje, probablemente pudieron contener sobre ellos una saywa, mojón o hito de piedra. Lo descrito permite entender el conflicto de las comunidades de Villablanca y Chulluncane, donde el amojonamiento de los deslindes está conformado principalmente por cerros, y enseguida, por vertientes, casas y apachetas.

Los amojonamientos son antiguas prácticas demarcatorias andinas (Molinié-Fioravanti, 1986-1987). Durante el periodo incaico, el amojonamiento o saywaña, según lo relatado por Puma de Ayala (1987), era de tipo "inductivo", es decir, iba de lo particular a lo general, empezando la demarcación por la unidad doméstica hasta llegar a los territorios étnicos. Para el periodo incaico, Harris (1997: 366-367) comenta:

"No sabemos si había alguna manera de diferenciar los mojones que señalaban derechos de uso, como de pasto o chacaras, de los que delimitaban jurisdicciones... todo debidamente registrado en quipus (que) se asemeja a un mapa en cuanto a sus funciones".

Durante el periodo colonial, al parecer el amojonamiento hispano fue inverso al procedimiento incaico, es decir, fue de tipo "deductivo", pues se inició por las grandes jurisdicciones administrativas, posteriormente se ocupó para escalas menores de tierras hasta llegar al ámbito doméstico. El orden colonial determinó los límites de los Corregimientos, amojonando la jurisdicción del Corregidor, demarcación que habilitó a las autoridades para nuevos actos administrativos, como el establecimiento de las jurisdicciones de las Doctrinas dentro de los Corregimientos, y los reconocimientos de tierras a españoles y aimara, posesiones que fueron amojonadas usando cerros, quebradas, ríos, vertientes y saywas (Dagnino, 1909). Según, BouysseCassagne (1987), el hispano impuso una racionalidad espacial que trasladó mecánicamente el ordenamiento administrativo de España a América. Este no tomó en cuenta el espacio real, ni la geografía, ni la ecología del territorio y menos el ordenamiento indígena. En efecto, a fines del siglo XVI la doctrina del virrey Toledo busca, como en España, agrupar en torno a pueblos a varios ayllus, y amojonar los límites entre pueblos o markas, y delimitar las tierras agrícolas y de pastoreo de los diversos ayllus. La fragmentación del espacio andino, primero por el establecimiento de los Corregimientos y Doctrinas y luego por la formación de pueblos por la política toledana, creó entre los aimara y en otros pueblos andinos, jurisdicciones territoriales que en algunos casos respetaron el parentesco y las tierras ocupadas, y en otros, produjeron reagrupamientos de familias en nuevas tierras, generando eventos de etnogénesis (Harris, 1997). Los "amojonamientos" y composiciones de tierras indígenas ya operaban a fines del siglo $\mathrm{XVI}$, delimitando territorios de ayllus en torno a una marka central o pueblo (Platt, 1978) ${ }^{6}$.

La formación de pueblos en el altiplano de Tarapacá, en la zona de Chulluncane y Villablanca, al parecer fue tardía. La tradición aimara, señala que la fundación de la iglesia

\footnotetext{
6 Según Olivia Harris, algunos mojones coloniales aun se visitan para los Carnavales por comunidades altiplánicas de Bolivia, como los ayllus de Yura, “...son idénticos a aquellos contenidos en una lista de 1590 de la doctrina de Yura, unos de los tres pueblos en que los wisijsa fueron reducidos por Toledo. Es decir, los mojones que se visitan en la actualidad son los de la nueva doctrina fundada en 1575". Agrega otro antecedente: "En general, las listas de mojones derivadas de la Composición de Tierras de 1646, a cargo de Josep de la Vega Alvarado, parecen delimitar territorios de grupos de ayllus en torno a un marka/pueblo de reducción. Tal es el caso de Sacaca, ya mencionado, y el de la lista de linderos y mojones de los ayllus de Macha de 1719, publicada por T. Platt" (Harris, 1997:366).
} 
de Cariquima, como pueblo y marka central, habría ocurrido en los primeros años del siglo XVIII. Lo mismo ocurre para la Iglesia del pueblo-marka de Isluga, que de acuerdo a Gundermann y González (1997) solo eran estancias ganaderas, pertenecientes al Curato de Camiña y colonizadas en el siglo XVII, conociéndose certeramente el uso y ocupación territorial de esta zona, en la cartografía colonial del siglo XVIII, analizada por Cunill (1972). Las estancias que dieron origen a las comunidades de Villablanca y Chulluncane, habrían tenido el mismo origen que las de Isluga, es decir, espacios colonizados por aimara procedentes de diversas localidades; en el caso de Villablanca, algunos de sus pobladores recuerdan haber llegado desde Sibaya, en la quebrada de Tarapacá.

En el periodo de la República del Perú y hasta 1879, funcionan los Juzgados de Paz en diversos pueblos andinos, como los de Camiña, Sibaya y Tarapacá, a los que concurren en 1873 las comunidades de Chulluncane y Villablanca, para resolver sobre deslindes y posesiones de tierras, en virtud del derecho consuetudinario y las evidencias de las ocupaciones históricas de tierras (Molina et al., 1997). Posteriormente, durante el siglo $X X$, bajo la ocupación chilena aparece la figura del Notario y el Conservador de Bienes Raíces asentado en la ciudad de Iquique, en las antípodas del altiplano. Estas autoridades constituyen profusamente en las primeras décadas del 1900 la propiedad aimara, y usan los deslindes como concepto jurídico demarcador de tierras en los títulos de propiedad. La falta de conocimiento de los territorios altiplánicos y la distancia geográfica y cultural, favorecen la formación de títulos de propiedad a discreción de los solicitantes aimara, que redactan deslindes muchas veces a interés del peticionario que generan una masiva superposición de títulos de dominio. Uno de estos traslapes de dominio es el conflicto entre las comunidades de Villablanca y Chulluncane.

\section{Conflictos, amparos, composiciones y conciliaciones de tierras}

Si bien las saywaña o amojonamientos de deslindes intentaban delimitar un reparto consentido, y crear vecinos, estas demarcaciones no estaban exentas de conflictos. Ya eran conocidos en los tiempos del Inca, pues "Ciertamente había reclamos y peleas sobre tierras, a pesar de todos los esfuerzos de imponer 'justicia' mediante los mojones" (Harris, 1997: 366-367). En lengua aimara, se nombran las palabras jutisiña, qurpasiña que significa "apartarse, desavenirse los amigos y dividir entre sí las tierras"; asimismo, "componer pleitos" se nombraba como pleitosirinaka achithapiña, jujikipaña, aruna waykukipaña. Finalmente, la palabra yatäsña implicaba "armarse, componerse, aderezarse", es decir, llegar a acuerdo (Bertonio, 1984: 374-358-122-308 y 519).

Durante los siglos XVI al XVIII, el amparo y las composiciones de tierras son aplicados a la constitución de propiedad y en situaciones de conflicto. El amparo de tierras operaba en cuestiones litigiosas, instrumento usado por la autoridad colonial para otorgar protección, resguardo o defensa de los terrenos a una persona, comunidad o ayllu, frente a terceros, indígenas o especialmente españoles ${ }^{7}$. La composición de tierras, por su parte, fue una institución jurídica española traída a América, que en el Virreynato del Perú ya operaba en el siglo XVI. Esta sirvió para confirmar títulos antiguos invocados por propietarios, para conceder nuevos títulos de propiedad de tierras adyacentes al primitivo, entrega de títulos a poseedores que las hubiesen tenido por más de 10 años, defensa y resguardo de las tierras de indios o comunidades, entrega o mensura de tierras realengas y baldías, y para subastas de estas (Campos, $1981)^{8}$.

\footnotetext{
7 Un ejemplo de amparo es el que recibe a inicios del siglo XVIII, el cacique Juan García Chuquichambe, gobernador del Pueblo de Chiapa "sobre unas tierras ubicadas en la parte baja, al pie del desierto, en la quebrada de Camiña (Tana o Camiña, Corza, Quiuña y Tiliviche), amenazadas por los españoles" (González y Gundermann 1997:24). Como este amparo, es posible encontrar en los siglos coloniales varios otros en la zona andina (Hidalgo, 1990).

8 Casos de composición de tierras para la zona andina son analizados para Arica y Tarapacá por Platt (1975) e Hidalgo (1990), las que sirvieron para consolidar la propiedad de tierras en manos de españoles, especialmente en Pica, Guatacondo, Camiña, Tilivilca, Quebrada de Tarapacá, Chiza, Chaca, Codpa, Suca, Azapa, Chacalluta y valle del Lluta,
} 
Durante los siglos XIX y XX, las repúblicas del Perú primero, y luego de Chile, aplican el nuevo ordenamiento jurídico que considera el mecanismo de la conciliación y la figura del "amigable componedor" que se ocupa en situaciones de conflictos de deslindes o posesiones de tierras en las zonas andinas. En el caso del Perú, los procedimiento de conciliación se realizan por medio de los Jueces de Paz, cargo que según la constitución peruana de 1823, sería ejercido por los alcaldes de las comunidades, "conociendo las demandas verbales, civiles de menor cuantía y criminales sobre injurias leves y delitos menores que merecieran una moderada corrección en las Prefecturas y Subprefecturas. Se debía administrar en cada localidad la 'justicia en nombre de la nación'". Estos Juzgados de Paz se encontraban distribuidos en las cercanías a pueblos y comunidades andinas, por tanto, conocían los conflictos y eran capaces de arbitrarlos ${ }^{9}$.

Con la ocupación chilena de Tarapacá en 1879, desaparece la institución de los Jueces de Paz, siendo reemplazada por la justicia común que se ocupará de materias de deslindes y conflictos de tierras y por los delegados territoriales. Sin embargo, el nuevo sistema de inscripción y dominio de la propiedad del Estado de Chile favorece la inscripción de tierras en las primeras décadas del siglo XX. En el altiplano de Arica-Parinacota y de Tarapacá, se constituyen 190 títulos de dominio aimara, con una superficie aproximada de 1,4 millón de hectáreas. De estos títulos "Colchane -la comuna donde se encuentran las comunidades de Villablanca y Chulluncane- posee un total de 38 propiedades con ocupación indígena" (MBN, 1998: 22). La inscripción de estos títulos, en muchos casos,

durante el siglo XVII (González y Gundermann 1997).

9 En 1872, los cargos de los jueces de paz en la zona aimara de Tarapacá eran los siguientes: "José Ramírez (Tarapacá), Mariano Chávez (Guatacondo), Eugenio Guacte (Laonzana), Manuel García (Guaviña), Manuel Pereira (Coscaya), Juan Barreda (Camiña), Ignacio Tauca (Miñi Miñi), Antonio Núñez (Sibaya), Andrés Ramírez (Limacsiña), Mariano Argote (Usmagama), Mariano Tayna (Sipiza), Rumaldo Esteban (Guasquiña), Tomás Yugra (Chiapa), Calixto Velarde (Mocha), Mateo Caquisane (Sotoca), Feliciano Mamani (Cariquima), Mariano Mamani (Isluga)" (La Estrella de Iquique, 28/11/2007). se efectuó redactando límites discrecionales que provocarán la sobre imposición de dominios desatando conflicto de tierras, entre los que se contarán a las comunidades de Villablanca y Chulluncane.

Con posterioridad a la constitución de la propiedad y los traslapes de dominio, vendrán las discusiones entre comunidades que intentaron alcanzar acuerdos de conciliación y convivencia, avalados por autoridades judiciales, políticas, administrativas o por las propias comunidades. Solo en 1993, la Ley Indígena 19.253, consideró en su Título VII el acápite

"De la Conciliación y del Procedimiento Judicial en los Conflictos de Tierras". Señala su Artículo 55, que "para prevenir o terminar un juicio sobre tierras, en el que se encuentre involucrado algún indígena, los interesados podrán concurrir voluntariamente a la Corporación a fin de que los instruya acerca de la naturaleza de la conciliación y de sus derechos y se procure la solución extrajudicial del asunto controvertido...".

Este artículo será invocado por las comunidades de Villablanca y Chulluncane para intentar resolver el conflicto de deslindes. Pero, cuando se realiza la primera visita del proceso de conciliación, las comunidades se presentan separadas, una en el morro Templanza y la otra en el cerro Chotocollo, dando cuenta de un acto material y simbólico de reivindicación de deslindes, que no admitirá acercamiento, ni acuerdo.

\section{El conflicto de tierras en los ayllus de Villablanca y Chulluncane}

Los territorios altiplánicos ocupados por las comunidades aimara de Villablanca y Chulluncane, eran tierras baldías al momento de la llegada de los españoles, según plantean González y Gundermann (1997). Sin embargo, el territorio estaba debidamente deslindado por jurisdicciones étnicas desde tiempos incaicos. Estas eran tierras del $\mathrm{CO}^{-}$ Ilasuyu amojonadas por el Inca Apo Maita Inga, conquistador de la provincia de Charca, quien "tuvo desde la ciudad del Cuzco todo 
el reyno del Collau sugeto y amojonado" (Waman Puma de Ayala, 1987:144; Harris 1997: 365). Los aimara ocupantes de estos territorios altiplánicos, formaban agrupaciones étnicas territoriales (Saignes, 1986; Hidalgo y Durston, 1998). Los de más al sur correspondían a los Carangas, grupo étnico al que solo se le sitúa en Urcosuyu, pero otros autores señalan que parte de los Carangas también ocupaban la quebrada de Tarapacá, con los que se completaría la distribución entre el altiplano y los valles altos y bajos (Gundermann y González, 1997). Las tierras de Villablanca y Chulluncane, cercanas a Cariquima, en los inicios del periodo colonial quedaron formando parte del Corregimiento de Arica y en el límite del Corregimiento de Charcas.

\section{El origen de las tierras de Villablanca y Chulluncane}

No está claro si existió en el altiplano de Tarapacá propiedad o asentamiento en el periodo colonial temprano, siglo XVI, específicamente donde se encuentran los pueblos de Isluga y Cariquima. Al sur de ellos, están las tierras en disputa que estudiamos, cuyos primeros títulos de propiedad aun es difícil saber sus años de constitución. Los papeles presentados por los miembros de la comunidad de Villablanca poseen dos timbres coloniales, en uno se lee: "León Dragón Rei de CastillaJuez Mayor. 1580-Prov.Tarapacá", y en el otro. "Ascencio Gutiérrez -RPVC. Tarapacá Capital Lima - Alcalde de Comunidad -Alto Perú", pero no hay referencia alguna a estos contenidos en la escritura. El relato histórico aimara señala que la gente de Templanza -que forma parte de la actual comunidad de Villablanca- provenía de las quebradas altas de Tarapacá y habrían Ilegado a fines del siglo XVII o principios del XVIII. "Mi abuelo Anacleto era de Sibaya, actualmente sus restos están allá, su familia... Anacleto Chambe era ganadero ahí -aparecen nombrado en la primera escritura de 1712-. Vino buscando salir por la cordillera, de Sibaya páacá y se vino a estacionar en Templanza. En ese tiempo no había Cariquima, nada, pero había gente" (Agustín Chambe, abril de 1997; Molina et al., 1997: 21).

A principios del siglo XVIII, se tiene la certeza de la existencia de escrituras de estancias y posesiones que nombran demarcaciones o amojonamientos, que separan a uno y otro linaje. Se trata de tierras cedidas o concesionadas en Templanza -parte de la comunidad de Villablanca- por el Rey de España en 1712. Esta presenta los primeros amojonamientos o deslindes conocidos entre Villablanca y Chulluncane:

“...Concesionario Rey Corona de España, celebrado en 30 de Abril de 1712 Don Tomás Chambe, Anclaceto Chambe natural 'de Templanza a Culluctaña' más otras casas habitadas con sus respectivas chacras, sembríos de quinoas y cebada en cuatro corrales, canchón de piedra con su riego de agua un canal grande de punto denominado Japuinto apo pueblo Culluctaña en Guañacucho en una chacra sembrío de quinoa en Atipa chacra sembrío en el Rincón de Tacore, chacra sembrío papa más con deslinde, con su vecino Matías Challapa, Anacleto Challapa otros Al Este Cerro Grande Oje, al Oeste Cerro Cruzane cumbre más alta, queda en misma línea, al Sur Cerro más alto Tocore Cruz Pucro, vertiente Pomarca más 4 casas habitadas, más viviendas con sus respectivas casas denominadas Añahuane, con un sembrío de chacras, quinoa, papas, vivienda Ancocahuane y Lacalacane, Norte con Vinto Cacalinca, corrales de corderos, ahí finalizan y terminan los deslindes de los señores Chambes" ${ }^{\prime 10}$.

Esta demarcación colonial estuvo rodeada de un conflicto de poder. La tradición y memoria histórica da cuenta de contradicciones entre los linajes Chambe y Challapa, en torno a la fundación del pueblo central, que posteriormente será Cariquima. "Mi abuelo Tomás Chambe, quería fundar el pueblo aquí en Templanza. Hicieron capilla, iglesia, torre, todo. En Cariquima también. Entonces discutieron. Unos querían allá, otros querían aquí. Apoyaron Ancuaque, todos, menos los Challapa (de Chulluncane)". La contradicción se resolvió por medio de un antiguo rito andino, lanzar un bastón al aire, el " $\mathrm{Ri}^{\text {", }}$ y donde se enterrase allí debería fundarse

\footnotetext{
${ }^{10}$ Constancia de deslindes y herencia celebrada ante la Oficina de Juzgado de Paz en Tarapacá, Juez Andrés Loaiza, a 10 de enero de 1873.
} 
el nuevo pueblo, señalan los miembros de la comunidad de Villablanca. El bastón se enterró en Cariquima, porque el terreno en Templanza era duro. "Después, mi abuelito quedó aquí con dolor por la derrota. Esa vez apoyaba a los Chambe, Ticuna de Oratorio, Añaguane" (Agustín Chambe, abril de 1997; Molina et al., 1997: 22). El trance por la fundación del pueblo es un antecedente de las contradicciones territoriales y de linajes, que se proyectarán hasta la actualidad. Los que apoyaban a los Chambe de Templanza, son familias de dos pequeños lugares cercanos: Oratorio y Añaguane. Los tres pueblos darán origen en 1945 al pueblo de Villablanca. Por su parte, los Challapa ganan la fundación de la marka central en Cariquima, un lugar ocupado por su linaje. Es decir, la contradicción y conflicto en el siglo XVIII se expresa a través de la fundación del pueblo central, divergencias que más tarde se traducirán en conflicto de tierras.

\section{Deslindamientos ante los Jueces de Paz del Perú. Siglo XIX}

En 1873, los propios interesados de Templanza (Villablanca) y Chulluncane, Ios Chambe y los Challapa, respectivamente, concurren ante el Juez de Paz de Tarapacá, Andrés Loaiza, para dejar constancia de los deslindes que separan sus posesiones y amparar en dichas tierras a sus hijos hombres, pues entre los aimara la herencia se da preferentemente por línea masculina, marginando a las mujeres del dominio hereditario ${ }^{11}$. El Juzgado de Paz, deja aclarado los deslindes y los derechos territoriales de cada cual.

"Constancia relativos de las propiedades... conforme el artículo 880 del código

\footnotetext{
11 En la constancia se escribe lo siguiente sobre los derechos de herencia: "Consta legalmente dejo amparo de terrenos, predios, pastales a mis hijos legítimos José María Challapa, Bonifacio Challapa, Mariano Cruz Challapa y ahí finaliza termina que fue transado ambos interesados Chambe y Challapa".

"Consta legalmente, dejo amparo, sobre tierra, predios, pastales a mis hijos legítimos, Lorenzo Chambe, Sebastian Chambe, Juan Chambe y a mis nietos Tara, Viza nietos. En, Constancia de deslindes y herencia celebrada ante la Oficina de Juzgado de Paz en Tarapacá, Juez Andrés Loaiza, a 10 de Enero de 1873.
}

civil del Perú, habiendosé sentenciado al fín ser dueños de las propiedades predios a punto, estancias Chuhuallame y Culcujaya Toruna y pastizales grandes con sus potreros, vegas grandes y la pampa Quilpilga y vertiente Chijulla, Vilque, Teipehuano, examinaron para legitimar legalmente la líneas de deslindes con sus vecinos Chambes. Al Sur con el Cerro Sillaguaya, al Norte Alto Tocore y Cruz queros, vertiente Pumarca, al Oeste Cerro Cruzane, los señores Matías Challapa son los propietarios con los señores Francisco Challapa mayor y menor, Melchor ChaIlapa son los propietarios y dueños de predios Chuhuallane y Culcujaya y cuyos deslindes son los siguientes. Son vecinos de los señores Chambes, 'al Oeste Cerro Oje, al Este Cerro Cruzane, las altas cumbres y Norte Alto Tocore Cerro, Cruz Pucro y Vertiente Pomarca, al este Cerro Morado Chognacota"12.

El Juez de Paz redacta en la constancia que "examinaron [las tierras] para legitimar legalmente la líneas de deslindes con sus vecinos Chambes". Es decir, una diligencia con conocimiento de la geografía del lugar y de los linajes poseedores de tierras, que les permite ratificar y redactar deslindes y amojonamientos claros y sin sobreimposiciones. El Juez de Paz, en este caso, redacta una escritura de dominio, con límites claros, nombrando cerros y una vertiente, todos reconocibles en el paisaje, erguidos como mojones comunes para ambas comunidades. Al final de la escritura, el Juez de Paz escribe: "Consta legalmente dejo amparo terrenos, predios, pastales a mis hijos legitimos José María Challapa, Bonifacio Challapa, Mariano Cruz Challapa, y ahí finaliza termina que fue transado ambos interesados Chambe y Challapa".

\section{El Estado chileno y la constitución de la propiedad aimara en Chulluncane $y$ Villablanca}

Después de la Guerra del Pacífico de 1879, la Región de Tarapacá quedó en poder

\footnotetext{
12 Idem. nota 5.
} 
del Estado chileno, que aplicó una política de inscripción de títulos de dominio a discreción de los solicitantes, quienes señalan los deslindes que constituyen el cuerpo cierto de la escritura de dominio, sin confirmar la justeza de lo reseñado. Esto lleva en 1912 a Esteban Challapa ante Francisco Subercaseaux, Notario y Conservador de Iquique, donde realiza una transacción de tierras, comprando a Mariano Cruz Challapa, uno de los herederos de la escritura del 1873, a quien adquiere el predio "Chuvallane". El predio adquirido está "ubicado en Cariquima, Subdelegación Undécima de Tarapacá con sus casas y aguas de riego", para luego proceder a inscribir el dominio del predio "...en virtud de haberse dado cumplimiento a lo dispuesto en el artículo 58 del Reglamento del Conservador de Bienes Raíces, habiéndose hecho publicaciones en el Diario El Nacional y fijándose en esta oficina el cartel que bajo el numero 173 dejo agregado al final del presente Registro"13.

Sin embargo, Mariano Cruz Challapa vende a Esteban Challapa un predio con deslindes distintos a los señalados en la escritura de 1873. Con ello, sobrepasa los amojonamientos anteriores, incorporando en la nueva escritura tierras ocupadas por las familias Chambe y Mamani (de la actual Villablanca) en el sector de morro Templanza y más abajo de la vertiente Pomarka. El predio "Chuvallane" constituido en 1912, se apropia por la vía legal de tierras de sus vecinos: "deslinda: Al Norte, Ojo de agua La Calacane y un morro en ciénaga de Templanza; al Sur, punta del Cerro Sillaguaya; al Este, punta del Cerro Blanco y Cerro Characollo; y al Oeste, Apacheta de Chijulla y ojo de agua de Panalla"14. Este nuevo deslinde incluye las tierras de Templanza de los Chambe y los pastizales de Añaguane, Lacalacane y Armasaya de posesión de los Mamani. Con la nueva escritura de dominio y la redacción por sí y ante sí de novísimos deslindes, se inicia el conflicto de tierras intraétnico.

\footnotetext{
${ }^{13}$ Compraventa Mariano Cruz Challapa a Esteban Challapa. Inscrita a Fojas $457 N^{\circ} 545$ del Registro de Propiedades del Conservador de Bienes Raíces de Iquique, del año 1912.

14 Compraventa Mariano Cruz Challapa a Esteban Challapa. Inscrita a Fojas $457 N^{\circ} 545$ del Registro de Propiedades del Conservador de Bienes Raíces de Iquique, del año 1912.
}

Los Mamani intentan en el año 1915 una primera negociación con Esteban Challapa, pidiendo se les devuelvan legalmente las tierras incluidas mañosamente en la inscripción de 1912. Esteban Challapa, es un aimara que sabe leer y escribir castellano, y figura como conocedor del poder y la nueva administración jurídica chilena. En 1922, parece allanarse a la devolución de tierras mediante el pago ofrecido por los Mamani, que da lugar a una compra de tierras, que realizan ante el inspector de Cariquima. Cuando llega el turno de legalizar la compraventa en Iquique, el trámite no se concreta por no asistir Esteban Challapa, que ya estaba enfermo. Actualmente, la comunidad de Chulluncane, a través de sus dirigentes, no reconoce el acuerdo y venta de 1922. "...el Notario no aceptó -la compraventa- ya que se requería la presencia del interesado [Esteban Challapa]", dice un comunero de Chulluncane ${ }^{15}$. De esta frustrada compraventa los miembros de la Comunidad de Villablanca recuerdan que sus abuelos, con motivo de la fiesta de San Miguel que se celebraba por los Challapa en Chuallane (o Chullancane) y en Añaguane, por los Mamani y Chambe, fueron a exigir cumplir el acuerdo de compraventa y la entrega de las tierras, amenazando a Esteban Challapa:

"Al final, como en la fiesta la gente empezó a exigir: 'ya bueno, lo vai a pasar o no' a lo que Esteban Challapa constestó: 'No pues señor, es que estoy dejando pasar el tiempo no más. Si los documentos están a mi nombre ahora así qué me van a hacer. Yo soy el que manda el documento, yo soy el dueño ahora (...) Al tiempo, como era mucho lo que estaban reclamando, Estaban Challapa dijo: 'saben qué más, yo no quiero estar aquí ya... Páguenme en animales, en charki, en todo... Le sacó el pago a la comunidad [Villablanca]- a cambio de traer a la venta la propiedad. Hizo, compromiso, todo... Entonces este señor dijo: 'saben, yo voy a desligarme de acá. Yo estoy endeudado con ustedes y les voy a pasar la Venta" (Bernabé Mollo, Villablanca, 12 de abril de 1997, en: Molina, 1998: 73).

\footnotetext{
15 Celestino Challapa. Chulluncane, 8 de abril de 1997 (Molina et al., 1998: 73)
} 
Pero, la devolución de tierras no ocurrió. Esteban Challapa fallece el 29 de octubre de 1923. Ese mismo año, en la Notaría de Iquique, comparecen los señores Clemente, Teodoro, Lorenzo, Genaro y Francisco Challapa, y Juan de Dios y Luis Mamani, para reducir a escritura pública el mismo contrato, inscribiéndolo como "Comunidad de Clemente Challapa" que reconoce el dominio de las tierras vendidas a los Mamani de Villablanca. El título de Esteban Challapa de 1912 quedará intestado, y luego del acto de reconocimiento de 1923, no se volverán a reivindicar tierras de posesión de la comunidad de Villablanca, abriéndose un periodo de conciliación y acuerdo para establecer deslindes en virtud del derecho consuetudinario aimara y las ocupaciones históricas.

La propiedad aimara constituida en Chulluncane en 1912, perteneciente al título de Esteban Challapa, va a coexistir con otros títulos de propiedad que conforman otras familias Challapa del mismo Chulluncane. Lo mismo ocurre con los títulos de tierras que forman parte de los Chambe y Mamani de ViIlablanca. Con excepción de las tierras intestadas de Esteban Challapa, los demás títulos de propiedad entre 1923 y 1950, serán objeto de numerosas ventas de tierras y reagrupaciones de títulos en ambas comunidades aimara. Los títulos de unos y otros miembros de estas comunidades no podrán hacerse efectivos como posesión material debido a la superposición de algunos de ellos, por lo cual se intenta arribar a acuerdos de conciliación y demarcación de deslindes con nuevos amojonamiento o saywas, que favorezcan la convivencia y reparen las maltratadas relaciones vecinales.

\section{Conciliaciones territoriales (1944-1975)}

En 1944, se produce el primer acuerdo de trazado de deslinde y convivencia entre algunas familias Challapa de la comunidad de Chulluncane $^{16}$, con los Chambe y Mamani

16 El documento está firmado por Clemente Challapa, Genaro Challapa, Silverio Challapa, Secundino Challapa, Feliz Challapa, Simeón Challapa, Toribio Challapa, Lorenzo Challapa y Francisco Challapa, de Villablanca. El acuerdo fue certificado por el Inspector del Cuarto Distrito, en el Pueblo de Cariquima.

"Primero. Los señores comuneros ChaIlapa que aceptan vivir armónicamente con los señores Chambe y Mamanes de Añabane. Artículo Segundo, se constituirán los siguientes deslindes por el medio de esta propiedad. Primero Ancocollo es deslinde para ambos lados, después sigue Cerrito de Chapasane, después sigue medio Belacollo, después sigue Viscachiri, deslinda por ambos lados y después sigue al lugar denominado Chorivinto, después al mismo camino principal del pueblo Mamal Samaña, (...) para vivir en amigablemente sin disgusto ni ofensa ninguna forma para que no haya ningún disgusto ni por otro ni por otra..." (Acta Aclaratoria de 14 de octubre de 1944) ${ }^{17}$.

En este acuerdo los deslindes continúan respetando el amojonamiento que provenía del tiempo del Perú. Incluso logran resolver el desacuerdo respecto de los hitos o mojones en la zona de Armasaya y Chotocollo, en que "los interesados de Challapa quedó anular el punto denominado Cerro Armasaya y a los otros de los interesados de los Chambe también anular el punto denominado Chotocollo" (Acta Aclaratoria de 14 de octubre de 1944).

Al parecer, los deslindes establecidos en la conciliación de 1944 no fueron suficientes para impedir los problemas con la ocupación de algunas tierras para el pastoreo y la agricultura. Con el fin de superar estos impases, las comunidades de Villablanca y Chulluncane acuerdan en el año 1954 en el

\footnotetext{
de Chulluncane. Testigos son: Juan P. Ticuna, Hilario Challapa, Ciriaco Gómez y Pedro Mamani, Protocolización en Notaría y Conservador de Bienes Raíces, Comercio y Minas, Archivero Judicial don Audilio Jiménez Gamonal. Iquique 28 de enero de 1946.

17 El documento está firmado por A. Graciano Chambe, Bentor Chambe, Gregorio Chambe, Julián Chambe, Justino Chambe, Juan de D. Mamani, Florencio Mamani y Patricio Mollo. Protocolización en Notaría y Conservador de Bienes Raíces, Comercio y Minas, Archivero Judicial don Audilio Jiménez Gamonal. Iquique 28 de enero de 1946.
} 
pueblo de Cariquima, un nuevo y definitivo arreglo que establece:

\begin{abstract}
"Hemos acordado fijar un deslinde para nuestras propiedades o terrenos que se encuentran vecinos, deslinde que debe ser respetado por ambas comunidades (Chulluncane y Villablanca) y sus sucesores por toda la vida. Dicho deslinde que dividirá nuestras propiedades en toda su extensión consta de una línea imaginaria que empieza en el punto Alto Talcane, Cerro Blanco de Este al Oeste, entre medio de esta división se hicieron veintidós linderos para respetarse ambos interesados... En la segunda no habrá ningún despojos por partes de ganado ni de regadío de agua siempre en costumbre de vivir como antes, quedaron de acuerdo ambos interesados". Este acuerdo es firmado por 21 comuneros de Villablanca y 14 comuneros de Chulluncane ${ }^{18}$.
\end{abstract}

Uno de los firmantes del acuerdo, Agustín Chambe, recuerda cómo se implementó el deslinde por medio de saywas o mojones. "Se hicieron monolitos por ambas comunidades, una línea de morritos de piedra. Alto Tancañe, más abajito un cerrito colorado, ahí tenemos un lindero, después Guaivarane, Japulla hay otro lindero, más arriba, Ocollere en la 'lomaita' hay otro lindero, en medio del potrero otro, después medio Taipicagua, Alto Tocore, Mamal Samaña, Chotocollo, Viscachiri, después medio Belacollo, Chamacanhuano, Marancelane, Oncollo" (Agustín Chambe, 30 de mayo de 1997, en: Molina et al., 1997: 86)

\footnotetext{
18 Acta firmada ante Alberto Castillo Rojas, Inspector del $4^{\circ}$ Departamento de Cariquima. Los firmantes son: Agustín Chambe, Juan de D. Mamani, Martín C. Mollo, Justino Chambe, Gregorio Chambe, Martín Mollo, Patrocinio Mamani, Nicolás Mamani, Patricio Mollo, Pedro Mamani, Florencio Mamani, Rosalío Mamani, Melitón Mamani, Eugenio Mamani, Pedro Chambe, Calixto Mollo, Vicente Mamani, Fermín Mamani, Ciriaco Mamani, Saturnino Mamani y Tomás Mollo por la comunidad de Villablanca. Simeón Challapa Chambe, Clemente Challapa M., Francisco Challapa G. Genaro Challapa, Toribio Challapa, Alberto H. Challapa, Juan Challapa G., Francisco Challapa Mamani, Emiliano Challapa E. José Mario Challapa Chambe, Silberio Challapa Chambe, Feliciano Challapa Esteban, Lorenzo Challapa M. y Vicente Challapa E. por Chulluncane.
}

Este deslinde fue confirmado por los miembros de la comunidad de Chulluncane, Simeón Challapa Chambe y Clemente Challapa Mamani, quienes el 22 de octubre de 1949 compraron los predios "Cullujtaña", "Chuhuallane" y "Vilque" a Francisco Challapa Mamani, título que se superponía a la posesión de 1912. "El precio de venta fue la suma de diez mil pesos moneda corriente, al contado. -La publicaciones respectivas se efectuaron en el diario "El Tarapacá", de esta ciudad, en sus ediciones de los días 30 de Noviembre, 1 y 2 de diciembre último $(1949)^{\prime \prime 19}$. En virtud de este dominio de tierras, concurrieron a firmar el acuerdo conciliatorio del año 1954, que estableció deslindes claros en virtud de las propiedades.

Los acuerdos de 1944 y 1958 permitieron a través de la demarcación de deslindes, la convivencia pacífica durante dos décadas. Fue en el año 1975 cuando un heredero de Esteban Challapa, mediante la posesión efectiva de la herencia intestada, logró revalidar el título de propiedad de 1912. Esto vino a cambiar nuevamente el cuadro de la convivencia entre ambas comunidades. El heredero de Esteban Challapa comenzó a reivindicar los deslindes de la inscripción de 1912, uno de ellos, el morro Templanza, que estaba en las tierras de posesión material de la comunidad de Villablanca. El documento de inscripción de herencia señala lo siguiente:

"Iquique, 10 de Abril de 1975.

Don Eugenio Juan Challapa, es heredero de los bienes quedados al fallecimiento de don Esteban Challapa, en su calidad de nieto legitimo del causante, en virtud de habérsele concedido la posesión efectiva de su herencia por auto inscrito en este mismo registro a Fojas 266 vuelta, $N^{\circ} 283$, con fecha de hoy.

Corresponde al heredero nombrado derecho de dominio en el predio denominado "Chuvallane", ubicado en Cariquima, Subdelegación Undécima de Tarapacá, con sus casas y aguas de riego, que deslinda: al norte, Ojo de agua La Calacane y un morro en ciénega de Templaza; al Sur,

\footnotetext{
${ }^{19}$ Registro de Propiedad del Conservador de Bienes Raíces de lquique, a fojas $100 \mathrm{vta}$. №95.
} 
punta del Cerro Sillaguaya; al Este, punta del Cerro Blanco y Cerro Charcollo; y al Oeste, apacheta de Chijulla y ojo de Agua de Panalla. El título de dominio del causante se encuentra inscrito en el Registro de Propiedad del Conservador de Bienes Raíces de este Departamento, a fojas 457, bajo el número 545, con fecha 17 de Octubre de 1912" 20 .

Como se puede apreciar, el título de propiedad de 1912 reclama como deslinde el morro Templanza, adentrándose unos tres kilómetros más al norte de la línea amojonada en la conciliaciones de 1944 y 1958. Con esto nuevamente se desestabiliza la convivencia y se reinaugura el conflicto, que como podemos apreciar tiene una profundidad de más de cien años. La comunidad de Chulluncane se divide entre herederos del título de 1912 y los que constituyeron dominio en 1949, ambos títulos superpuestos entre sí en un 80\%. El predio de 1912 es "Chuallane" que se superpone a las tierras de Villablanca hasta el morro Templanza, y los otros son los predios "Cullujtaña", "Chuhuallane" y "Vilque" de 1949, que logran definir claramente los deslindes con Villablanca. Estos últimos propietarios son quienes han venido realizando las conciliaciones de la década de 1950, pero a partir del año 1975, fueron impugnadas sus competencias por Eugenio Challapa, heredero y propietario del título de 1912, que entró en conflicto con los comuneros de Villablanca.

La última conciliación entre Villablanca y Chulluncane se efectuó en el año 1987, la que consistió en aclarar los derechos de pastaje en el bofedal y establecer la línea definitiva sobre algunos terrenos. En esta conciliación participó Simeón Challapa Chambe, como propietario del título de 1949, pero el acuerdo fue impugnado y desconocido por el heredero del título de 1912, Eugenio Challapa, quien siguió reivindicando tierras hasta el morro Templaza. Los herederos del título de 1912, comuneros de Chulluncane, en el año 1996 exigieron una nueva conciliación en

\footnotetext{
20 Inscripción de herencia, Eugenio Juan Challapa, a Fojas 267, N³84, del Registro de Propiedades del Conservador de Bienes Raíces de Iquique, del año 1975.
}

virtud de lo establecido por la Ley Indígena $N^{\circ} 19.253$ de 1993. Cuando concurrieron las autoridades del Estado a dar inicio al proceso de conciliación, se encontraron que los litigantes no estaban juntos para discutir y llegar a acuerdos. Al contrario, los miembros de cada comunidad se encontraba separados, cada cual reunidos en el cerro que marcaba sus deslindes. Unos sobre el morro Templanza, los herederos del título de 1912 de Chulluncane, y los otros, los comuneros de Villablanca, en la cima del cerro Chotocollo. Sobre las cumbres de estos cerros se expresaba y renovaban la irreductibles posiciones territoriales, como lo describe el relato que inicia este artículo.

\section{Reflexiones finales}

El estudio de los conflictos territoriales andinos, desde una perspectiva geográfica diacrónica, vinculada a la tradición de la geografía histórica, permite comprender la dinámica de los procesos intraétnicos que son parte de la construcción de la territorialidad en el mundo andino. El uso de categorías geográficas referidas a las demarcaciones de tierras como saywaña, amojonamiento y deslindes, en contextos de época, son claves de considerarlos dentro de la perspectiva de la geografía cultural, la que permite comprender socialmente y en el terreno los contenidos de los documentos, y cómo estos expresan las contradicciones territoriales en el espacio.

En Villablanca y Chulluncane los demarcadores territoriales escogen lugares del paisaje como hitos delimitadores de espacios. Estos son a la vez fronteras materiales y simbólicas, en cuanto expresan jurisdicción territorial y dominio de uno o más linajes aimara. Estas demarcaciones se constituyen en líneas de separación y de convivencia intraétnica. Pero también las demarcaciones geográficas en el paisaje, son expresión de conflicto étnico y social, muchas veces sin solución y perdurable en el tiempo. Los deslindes, saywaña y amojonamientos, son visuales y deben ser reconocibles en el terreno. Ellos constituyen piezas de gran importancia para la geografía y la comprensión del mundo andino, en la medida que van repartiendo, separando y cerrando posesiones, que dan materialidad al espacio. 
Las demarcaciones territoriales no son azarosas entre las comunidades aimara, ellas constituyen un diseño cartográfico que localiza los amojonamientos que cobijan espacios cualitativos y cuantitativos, que consideran los recursos necesarios para sostener o incrementar sus economías familiares basadas en el pastoreo, la agricultura, la recolección y la caza. Por ello, desde tiempos prehispánicos, las saywañas, los amojonamientos y los deslindes han considerado en sus trazados en las zonas altiplánicas, la inclusión de campos de pastoreo, bofedales y vegas, lugares aptos para campos de cultivos, vertiente de agua para regadío y espacios para localización de caseríos, estancias y corrales. Este es justamente el origen del conflicto entre las comunidades de Chulluncane y Villablanca en el siglo $\mathrm{XX}$, donde existe un espacio en disputa de tres kilómetros de ancho, entre el morro Templanza y el cerro Chotocollo, el que contiene campos de pastoreo, zonas de cultivos y un extenso bofedal y vega, usado preferentemente para la crianza de alpaca, el ganado más cotizado por su valiosa lana. Pero, como plantea la geografía cultural, que no admite separación entre espacio natural y social, el conflicto estudiado no solo puede comprenderse por la existencia de recursos ambientales, sino también por factores de arraigo ancestral de los linajes aimara. Así, la posesión material de las familias de ViIlablanca y Chulluncane se ha comprobado que proviene a lo menos desde 1712, pero con deslindes no superpuestos. Solo en 1912, una fracción de familias de Chulluncane, en virtud de la creación de un título de dominio de modo discrecional, inscrito en el Conservador de Bienes Raíces de Iquique, generó la superposición de dominios y el conflicto que se proyecta contemporáneamente.

Por tanto, el factor detonante del conflicto geográfico cultural intraétnico en Chulluncane y Villablanca, si bien está en la inscripción de 1912, su aparición compromete a la política liberal de constitución de la propiedad que aplicó el Estado de Chile, luego de la ocupación de Tarapacá, tras la Guerra del Pacífico de 1879. El Código Civil y el Reglamento del Conservador de Bienes Raíces, ayudó a un proceso de creación de títulos de dominios de pequeños y grande predios, donde no existieron actos de verificación en terreno, favoreciendo la constitución de propiedades territoriales con deslindes superpuestos, que muchas veces fueron reflejo de antiguos conflictos o nuevos anhelos territoriales. Lo señalado, solo es posible desentrañarlo con un enfoque geográfico diacrónico-cultural, que indaga sobre el origen y las causas del conflicto, permite comprender el sentido material y simbólico del conflicto, y los detonantes del problema intraétnico en las comunidades aimara de Villablanca y Chulluncane. Esperamos así que el trabajo expuesto constituya un aporte desde la geografía histórica y cultural a los estudios andinos.

\section{Referencias bibliográficas}

BERENGUER, J. Caravanas, Interacción y Cambio en el Desierto de Atacama. Santiago de Chile: Sirawi Ediciones, 2004.

BERTONIO, L. Vocabulario de la lengua aymara. La Paz: CERES/IFEA/MUSEF, 1984 [1612].

BOUYSSE-CASSAGNE, T. La Identidad Aymara, Aproximación histórica (Siglo XV, Siglo XVI). La Paz: Biblioteca Andina, Serie Histórica. Hisbol, 1987.

BROWMAN, D. Tiwanaku expansion and altiplano economic patterns. Estudios Arqueológicos, 1980, № 5, p. 327-349.

CAMPOS, F. Tres casos de composición de tierras. Revista Chilena de Historia del Derecho, 1981, N8, p. 67-72.

CLAVAL, P. Los fundamentos actuales de la geografía cultural. Documents d'Analisi Geografica, №34, 1999, p. 25-40.

CUNILL, P. Fuentes cartográficas en la génesis de los tipos de poblamiento chileno. Siglos XVI al XVIII. Santiago de Chile: Apartado del Primer Symposium Cartográfico Nacional, Departamento de Geografía, Universidad de Chile, 1972, p. 141-144.

CUNILL, P. Desafíos de la Geografía Histórica en la Integración de los Andes y las zonas áridas. Diálogo Andino, 2014, No 44, p. 105-122.

CHOQUE, C. Conflictos sociales y políticos y su judicialización en una comunidad 
andina, Norte de Chile (1867-1925). Estudios Atacameños, 2015, Nº 50, p. 215-227.

DAGNINO, V. El corregimiento de Arica: 1535-1784. Santiago de Chile: Imprenta La Época, 1909.

DOLLFUS, O. Territorios andinos: reto $y$ memoria. Lima: Instituto de Estudios Peruanos, 1991.

FERNÁNDEZ, F. Geografía Cultural. En: HIERNAUX, D. y LINDON, A. (directores). Tratado de Geografía Humana. Barcelona: Editorial Anthropos - Universidad Autónoma Metropolitana, 2006, p. 220-253.

GODELIER, M. Lo ideal y lo material: pensamiento, economías, sociedades. Madrid: Editorial Taurus, 1984.

GREGORY, D. Geographical Imaginations. Oxford/Cambridge: Blackwell Publications, 1996.

GUNDERMANN, H. Comunidad aymara y conflicto interno sobre la tierra en la región de Tarapacá- Chile. Cuadernos Interculturales, 2005, Año 3, Nº 5, p. 43-66.

GUNDERMANN, H. y GONZÁLEZ, H. Contribución a la historia de la propiedad aymara. Santiago de Chile: Corporación Nacional de Desarrollo Indígena (CONADI), 1997.

HARRIS, O. Los límites como problema: Mapas etnohistóricos de los Andes bolivianos. En: BOUYSSE-CASSAGNE, TH. (compiladora). Saberes y Memorias en los Andes. In Memorian de Thierry Saignes. Lima: CredalIFEA, 1997, p. 351-573.

HIDALGO, J.; MARSILLI, M. y RUIZ, C. Composición de tierras en el corregimiento de Arica: la visita de Diego Baños y Sotomayor en 1643. Historia, 1990, Vol. 25, p.175206.

HIDALGO, J. y DURSTON, A. Reconstitución étnica colonial en la sierra de Arica: El cacicazgo de Codpa, 1650-1780. En: Actas del IV Congreso Internacional de Etnohistoria, Tomo II. Lima: Fondo Editorial Pontificia Universidad Católica del Perú, 1998. 32-75.
MARTÍNEZ, G. El sistema de los uywiris en Isluga. En: Homenaje al Dr. Gustavo Le Paige, S.J. Santiago de Chile: Universidad Católica del Norte, 1976, p. 27-88.

MARTINIC, M. y TAPIA, M. Sesquicentenario del Código Civil de Andrés Bello. Santiago de Chile: Editorial LexisNexis, 2005.

MINISTERIO DE BIENES NACIONALES (MBN). Plan de saneamiento para tierras aimaras y atacameñas de la I y II Regiones. Santiago de Chile: Documento de trabajo, 1998.

MOLINA, R. El Desierto-Despoblado de Atacama: Geografía e Imaginarios Coloniales. Santiago de Chile: Tesis para optar al Grado de Magister en Geografía con mención en Recursos Territoriales, Facultad de Arquitectura y Urbanismo, Universidad de Chile, 2010.

MOLINA, R.; CORREA, M.; CONCHA, R. y MANNS, M. Estudio para la conciliación territorial entre las comunidades Aymara de Chulluncane y Villablanca. Comuna de Colchane, Altiplano I Región. Grupo de Investigación Tepu, 1997 (Inédito).

MOLINIÉ F., A. El Simbolismo de frontera en los Andes. Revista del Museo Nacional, 1986-1987, Tomo XLVIII, p. 251-286.

MURRA, J. El control vertical de un máximo de pisos ecológicos en Visita de la Provincia de León de Huanuco en 1562 por Iñigo Ortiz de Zuñiga. Lima: Universidad Nacional H Valdizán, 1972.

MURRA, J. Los Limites y las Limitaciones del "Archipiélago Vertical" en Los Andes; Informe de Tema al simposio $N^{\circ} 2$ Verticalidad y Colonización Andina Pre-Europea. En: Serie Documentos de Trabajo $N^{\circ} 4$. Informes de Tema para los Simposios del Primer Congreso del Hombre Andino. Iquique: Programa de Arqueología y Museos, Departamento de Ciencias Sociales, Universidad de Chile, Sede Antofagasta, 1973.

MURRA, J. Formaciones económicas y políticas del mundo andino. Lima: Instituto de Estudios Peruanos, 1975.

NúÑEZ, L. Avísale, Freddy. Historia de un hombre y sus razones 1943-1973. Santiago 
de Chile: LOM Ediciones, Colegio de Antropólogos de Chile, 2015.

NÚÑ̃E, L. y DILLEHAY, T.S. Movilidad Giratoria, Armonía Social y Desarrollo en los Andes Meridionales: Patrones de Tráfico e Interacción Económica. Antofagasta: Universidad Católica del Norte, 1979.

PLATT, T. Mapas coloniales de Chayanta: dos visiones conflictivas de un solo paisaje. En: Estudios bolivianos en homenaje a Gunnar Mendoza. La Paz, 1978, p. 125-196.

PLATT, T. Estado boliviano y ayllu andino. Tierra y tributo en el Norte de Potosí. Lima: Instituto de Estudios Peruanos, 1982.

PUMA DE AYALA, W. Nueva corónica y buen gobierno. México: Edición de John Murra y R. Adorno, Editorial Siglo XXI, 1987.

RUZ, R. Tensión, asimilación y apropiación de lógicas escriturales y jurídicas en torno a la tierra indígena del Norte Grande Chileno. Siglos XIX y XX. En: DÍAZ, A.; RUZ, R. y GALDAMES, L. (compiladores). Tiempos Violentos. Fragmentos de la Historia Social de Arica. Arica: Ediciones de la Universidad de Tarapacá, 2014, p.143-147.
SAIGNES, T. Los Andes orientales: historia de un olvido, La Paz. Lima: Instituto Francés de Estudios Andinos /CERES, 1985.

SAIGNES, T. En busca del poblamiento étnico de los Andes bolivianos (siglos XV y $X V I)$. La Paz: Avances de investigación №3, Museo de Etnografía y Folclore, 1986.

SAIGNES, T. Ava y Karai. Ensayos sobre la frontera chiriguano (siglos XVI- XX). La Paz: Editorial Hisbol, 1990.

SAMARKIN, V. Geografía Histórica de Europa Occidental en la Edad Media. Madrid: Akal Editores, 1981.

SAUER, C. Hacia una geografía histórica. Discurso a la Asociación Norteamericana de Geógrafos. Baton Rouge, 1940. Traducción y presentación de Guillermo Castro H. Disponible en Internet:

http://www.colorado.edu/geography 